\title{
An Integrated Environmental Assessment of a coastal lagoon: The Case of the Oualidia lagoon (Morocco)
}

\author{
Mohammed Bouchkara, ${ }^{1, *}$, Nezha Mejjad ${ }^{2}$, Khalid El Khalidi ${ }^{1}$, Donata Melaku Canu ${ }^{3}$, and Bendahhou Zourarah ${ }^{1}$ \\ ${ }^{1}$ Marine Geosciences and Soil Science Laboratory (URAC-45), Earth Sciences Department, Faculty of Sciences, Chouaib Doukkali \\ University, BP 20, 24000, El Jadida, Morocco. \\ ${ }^{2} \mathrm{PhD}$, associate member of Marine Geosciences and Soil Science Laboratory (URAC-45), Earth Sciences Department, Faculty of \\ Sciences, Chouaib Doukkali University, BP 20, 24000, El Jadida, Morocco. \\ ${ }^{3}$ National Institute of Oceanography and Applied Geophysics - O.G.S., Borgo Grotta Gigante, 42/c, 34010 Sgonico TS, Trieste, Italy.
}

\begin{abstract}
This paper aims to present a comprehensive socio-economic and environmental analysis of the Oualidia lagoon in Morocco. This lagoon is classified as a RAMSAR site since 2005, providing valuable ecosystem services for the surrounding population. This paper followed the Drivers-Activities-PressuresState-Change-Impact-Responses (DPSIR) framework to evaluate environmental condition changes within the lagoon to support decision-making. The present research suggests a potential future model for safeguarding the lagoon's ecosystem without risking the well-being of future generations.
\end{abstract}

\section{Introduction}

Lagoons constitute $13 \%$ of the global coastline [1]. These are among the highest economically productive environments [2,3] and deliver numerous important environmental goods [4] that have a wide range of ecological, cultural, and socio-economic values which support several important natural services for human society $[5,6]$. They are widely regarded as the most precious components of the coastal zone [6]. However, coastal lagoons are undergoing substantial environmental degradation (Eutrophication, pollution, urbanization, and various forms of change) $[7,8]$.

The Oualidia lagoon complex is one of the most important coastal wetlands in Morocco. It is essentially made up of a lagoon, swampy areas, and salt marshes, all occupying an interdunal furrow limited to the East by a cliff 50-80 m high and to the West by a cordon of living dunes. It is also home to various exploitations with great ecological value (artisanal fishing, aquaculture, exploitation of natural deposits of mollusks, sand production, etc.).

This lagoon is a site of biological and ecological interest and, since 2005, it has become an international Ramsar site. It provides valuable socio-economic and environmental benefits to its population. Thus, the Oualidia lagoon is one of the Moroccan ecosystems directly affected by human factors [9-12], which requires management interventions to achieve sustainable blue growth.

We present here the analysis of the results, including social, economic, and ecological aspects, through a holistic and integrated management framework (DPSIR).

\section{Study Area}

The Oualidia lagoon is situated on the Moroccan Atlantic coast. It is located $75 \mathrm{~km}$ south of El Jadida city $\left(32^{\circ} 44^{\prime}, 42\right.$ $\mathrm{N}-9^{\circ} 02^{\prime}, 50 \mathrm{~W}$ ) (Fig.1). It is characterized by a warm temperate climate and an average rainfall, varying according to natural fluctuations in the rainfall regime.

This lagoon is among the most important coastal wetlands in Morocco. Today, in relation to its ornithological importance, this site has been classified as a site of biological and ecological interest (SIBE), through the Master Plan of Protected Areas and as a RAMSAR site since 2005. Of international value constitutes a migratory stopover and a winter refuge appreciated by the various species of water birds.

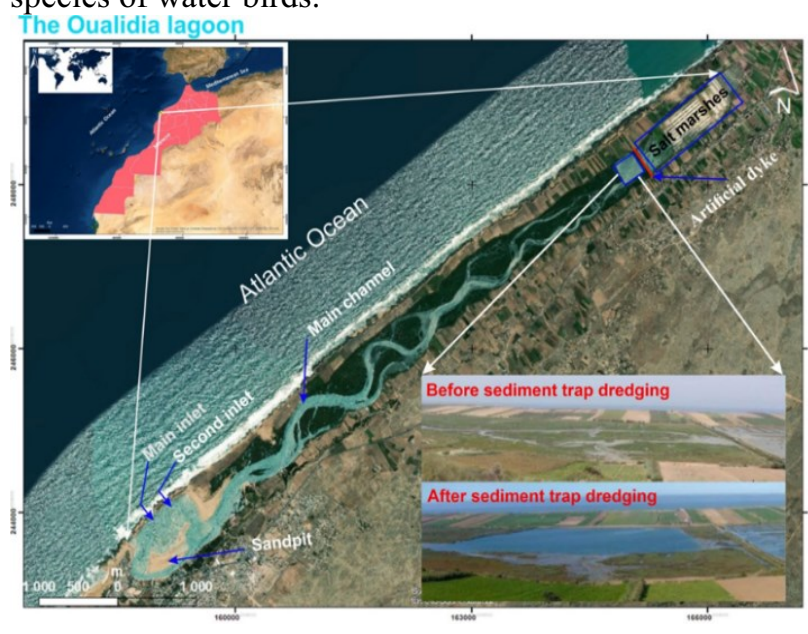

Fig. 1. The geographic location of the Study area

\footnotetext{
* Corresponding author: m.bouchkara@yahoo.com
} 


\section{Materials and methods}

The socio-environmental analysis of the Oualidia Lagoon was evaluated based on the DPSIR framework as an integrative management process tool [13]. This framework originated in the late 1990s [14]. The Pressure-StateResponse (PSR) framework was the early implementation of the DPSIR approach, which was suggested by [15] and further refined by the Organisation for Economic Cooperation and Development for Environmental Policy and Reporting [16]. Drivers-Pressures-State-Impact-Response (DPSIR) is a global issue structure model that the European Environment Agency has adopted in the 1999s to estimate the link between drivers, impacts, and policy responses $[13,17]$. The application of this model in our study is primarily based on a causal link between "driving forces" (economic sectors, population growth/land-use change), "pressures" (pollution, human activities), "states" (physical, chemical, and biological), and "impacts" on ecosystems, health, and human functions, ultimately leading to policy "responses" (managed projects, proposed projects).

\section{Results and discussions}

\subsection{Drivers, Pressures, and Impacts on the Oualidia lagoon}

The main anthropogenic drivers are the human activities practiced in and around the lagoon, as illustrated in (Fig. 2). Fishing, oyster culture, agriculture, urban and tourism activities are exercising many pressures on the lagoon, threatening its viability.

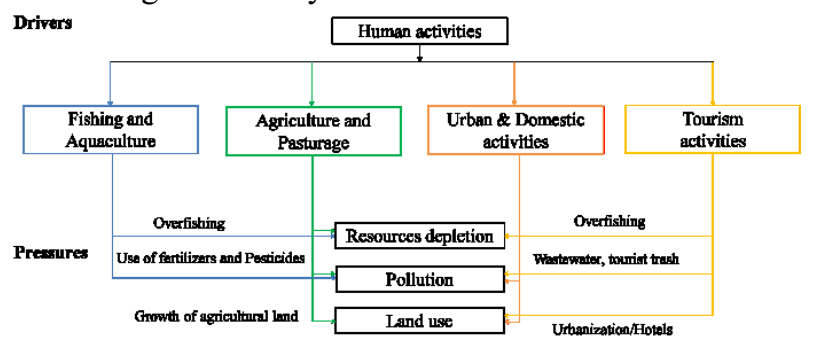

Fig.2. the main anthropogenic drivers and pressures in the Oualidia lagoon.

\subsubsection{Aquaculture}

The Oualidia lagoon is the historically important Moroccan aquaculture site. This activity is very relevant, especially oyster farming operated since 1970 in the lagoon [11]. Today, there are 8 oyster farms, and its annual production is about 200 tons of oysters. Nowadays, aquaculture activities encounter important issues caused by the deterioration of the environment due to various anthropogenic developments (organic and chemical pollution). This site, classified as Zone A, is now in Zone $\mathrm{B}$ and is at risk of being reclassified as Zone $\mathrm{C}$.

\subsubsection{Urbanization}

Oualidia Lagoon has experienced an increase in land use and population concentration since 1950 . The population density in Oualidia over the past 50 years has rapidly increased from 7,741 in 1971 to 13,076 in $1994,15,430$ in 2004, and 18,616 in 2014 (http://www.statistic.gov.ma/).

The change in land use can significantly affect runoff volume and heavy metal input (Maanan et al., 2014). Quantitatively, these effects are revealed for the entire watershed, and an assessment of land-use change was conducted by [11], who reported that in 2006, the main land cover types identified in the Oualidia Lagoon were agricultural areas $(40.15 \%)$, salt marshes $(25.29 \%)$, grasslands $(20.45 \%)$ and urban areas $(11.74 \%)$. The majority of the extension of urban areas was used for housing, businesses, institutions, infrastructure, and tourist areas [11].

\subsubsection{Tourism and recreation}

The Oualidia lagoon offers many tourist activities, including sailing, swimming on the beaches, bird watching, and nature observation. The seaside resort has a diversity of landscapes, and in summer, the population increases by 54,000 with a daily capacity of 30,000 people [18]. Touristic and recreational activities can cause environmental disturbances that can threaten biodiversity and ecological integrity.

\subsubsection{Salt extraction}

The salt marshes, covering an area of over 270 ha, play an important economic role. It is a process of artificialization of the wetlands of the lagoon, which started in 1949. The evolution of the salt marshes leads to the loss of wetlands containing the optimal conditions for biological life and the waste products abandoned there to distort the environment.

\subsubsection{Agriculture}

Farming is practiced in very narrow plots, on a strip bordering the wetland, both in the depressions and on the coastal dunes. In search of higher production, farmers remove fallow land from the agricultural rotation and intensify cultivation, using large quantities of chemical and organic fertilizers and phytosanitary products.

In the absence of a framework for rational input use, farmers overuse these products without respecting either the doses or the treatment periods. Drained by runoff water, all these products will contaminate the wetlands. 


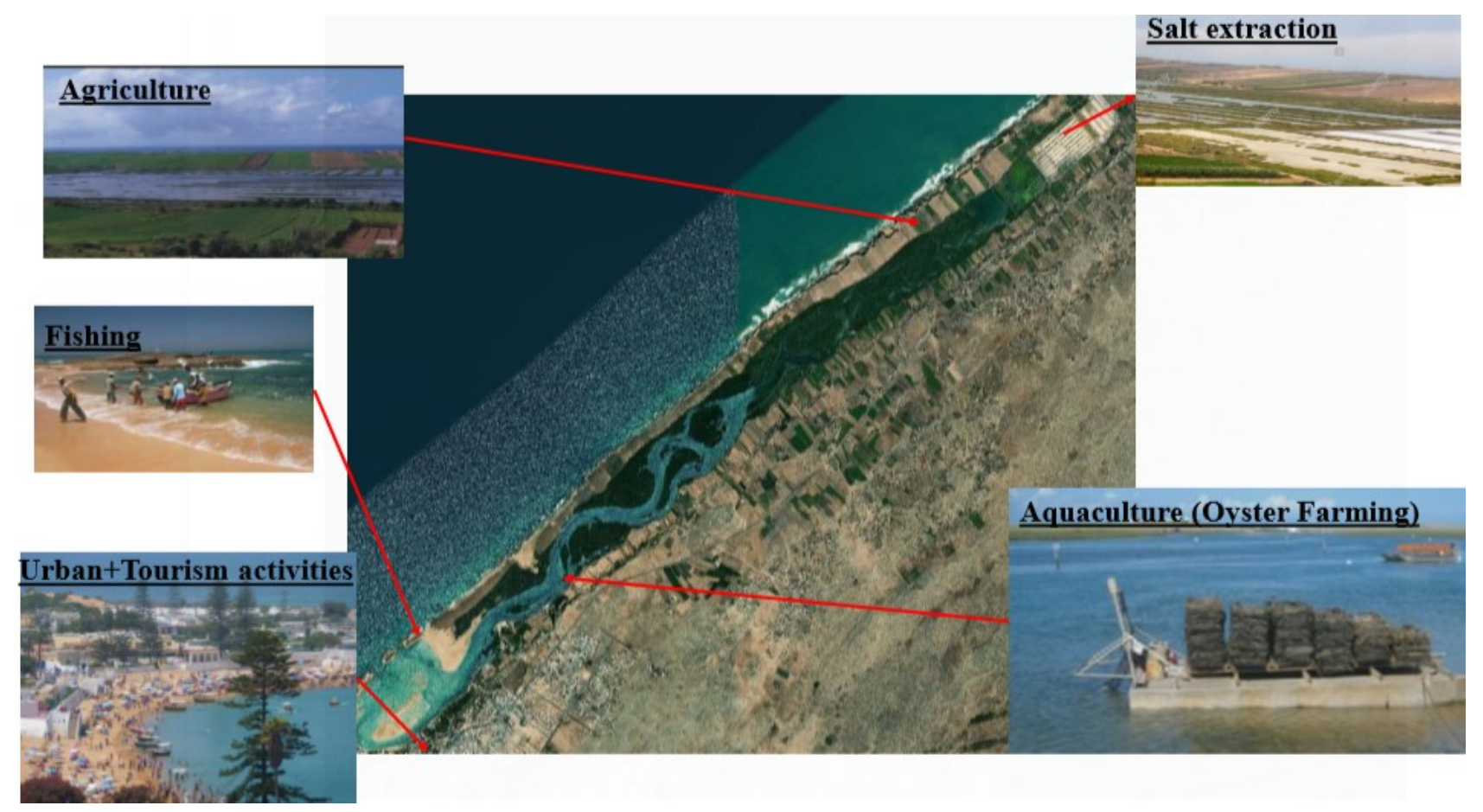

Fig. 3. The main human activities in the Oualidia lagoon

\subsection{Responses of Human society}

\subsubsection{Past Management projects}

Despite the qualities mentioned above of the Oualidia lagoon, local populations growth and their activities intensification have been accompanied by a substantial degradation of their activities in the absence of safeguard plans values. Biodiversity is under continuous stress, as well as economic resources. However, the impacts are not limited to the exploitation of the lagoon complex; they come largely from degradation processes that extend over the watershed. Scientists believe that the severity of these impacts must be strongly emphasized, mainly because of the high sensitivity of the lagoon environments.

Morocco launched the HALIEUTIS plan in 2009. This new strategy for the development and competitiveness of the marine fisheries sector aims to ensure the sustainability of the sector through the preservation of fisheries resources and to meet the challenges of globalization by meeting increasingly demanding standards.

Similarly, Morocco created the National Agency for the Development of Aquaculture in 2011, which developed environmental measures followed by the aquaculture industries [18]. The National Agency for Aquaculture Development is the main actor in the aquaculture industry to promote sustainable aquaculture along the Moroccan coast, including in lagoons.

In 2011, Planète Urgence initiated a mission in Morocco to protect the lagoon of Oualidia as a RAMSAR site. This mission is conducted in partnership with two local associations, the Association for the Protection of the Oualidia Lagoon (APLO) and the Integrated Management of Resources (AGIR) located in Al Hoceima, Morocco. Several actions have been planned to consider all the environmental problems of the lagoon, namely intensive agriculture, excessive use of fertilizers and pesticides, irrigation, overexploitation of aquaculture resources, etc. These actions include an annual survey of migratory and endemic birds in the lagoon, the collection of macro-waste in the lagoon and on the surrounding beaches (this collection will be done by snorkeling), and participation in the inventory pelagic marine species around the lagoon of Oualidia (http://ma.chm-cbd.net/news/protection-de-lalagune-d-oualidia).

\subsubsection{Creation of a sediment trap}

Considering many environmental problems such as the asymmetric nature of tidal propagation, the confinement of upstream waters, and the decrease in-depth, it was therefore advised in 2006 to create a sediment trap near the upstream dike in order to trap this sludge carried upstream by the strongest currents during the flow [19-22]. This sediment trap was constructed in 2011. Thus, the sediment trap construction facilitated the lagoon's hydrodynamics, especially in the sandpit area, which changed its morphology. This hydrodynamic resulted in a decrease in sedimentary organic matter upstream that is likely due to the trapping of fine sediments in the sediment trap [23].

\subsubsection{Best practice recommendations for integrated management}

Ecological monitoring system: Due to the importance of ecological conservation and its management, we propose to develop a simple ecological monitoring system as one of the main long-term measures, which will serve as a management and decision support tool. Thus, the installation of ecological monitoring stations is strongly recommended. These monitoring stations will be installed at different locations in the lagoon in order to continuously 
record all changes in the ecological parameters of the site (temperature, salinity changes, and other physicochemical factors), which could be the consequence of many human activities practiced at the site or of external natural trends such as climate change and morphological modifications of the inlets.

Monitoring of human activities: The economically viable natural resources of the lagoon of Oualidia are primarily derived from agriculture, aquaculture, fishing, tourism, and other associated activities.

- Fishing. Fishers use small-mesh boats and nets that allow them to catch fish of all sizes and shellfish. Therefore, the main pressures resulting from fishing are related to increasing the harvest of target fish and shellfish populations. This leads to their decline, which can also be exacerbated by illegal fishing and the use of illegal gear, lack of regulation, and insufficient controls. For this reason, the fishing activity must be monitored to highlight its different impacts on fish populations, birds, or the wetland environment in general.

- Agriculture. The monitoring system of this activity must allow the detection and evaluation of any impact on habitats (soil, water, plant groups, etc.) and species of fauna and flora.

- Tourism. Monitoring this economic activity will provide managers with information to justify these "uses" of space, which are not incompatible with nature conservation. In addition, EL Mahrad et al., 2020 proposed practical and feasible management measures to mitigate waste, including well-located trash cans, environmental advice for tourists, waste collection, and beach cleaning at the Oualidia lagoon in summer.

It is important to establish policy actions aimed at achieving a safe and unpolluted ecosystem, with a clear vision and feasible solutions, to present practical responses that contribute to reducing the degradation of the ecosystem's biodiversity and meet the needs of the local population.

\section{Conclusion}

The Oualidia lagoon is providing precious socio-economic benefits and ecosystem services for the local population. Nevertheless, the non-sustainable use of this ecological space has led to different types of degradation and numerous environmental problems.

The application of the DPSIR framework constituted a multidisciplinary approach that allowed us to outline the links between socio-economic activities, their impacts on the sustainability of the lagoon, and human interventions to reduce them, with a more strategic vision to improve the ecological productivity of the Oualidia lagoon, ensure the sustainability of its natural resources and integrated management of this ecosystem.

Responses were proposed as possible measures that could contribute to the sustainability of the Oualidia lagoon and its resources.

\section{References}

1. R. S. K. Barnes, Biol. Mar. Mediterr. 2, 3 (1995)
2. R. W. Duck and J. F. da Silva, Estuar. Coast. Shelf Sci. 110, 2 (2012)

3. B. Knoppers, in Elsevier Oceanogr. Ser. (Elsevier, 1994), pp. 243-286

4. M. Cañedo-Argüelles, B. J. Kefford, C. Piscart, N. Prat, R. B. Schäfer, and C. J. Schulz, Environ. Pollut. 173, 157 (2013)

5. A. Newton, A. C. Brito, J. D. Icely, V. Derolez, I. Clara, S. Angus, G. Schernewski, M. Inácio, A. I. Lillebø, A. I. Sousa, B. Béjaoui, C. Solidoro, M. Tosic, M. Cañedo-Argüelles, M. Yamamuro, S. Reizopoulou, H. C. Tseng, D. Canu, L. Roselli, M. Maanan, S. Cristina, A. C. Ruiz-Fernández, R. F. d. Lima, B. Kjerfve, N. Rubio-Cisneros, A. PérezRuzafa, C. Marcos, R. Pastres, F. Pranovi, M. Snoussi, J. Turpie, Y. Tuchkovenko, B. Dyack, J. Brookes, R. Povilanskas, and V. Khokhlov, J. Nat. Conserv. 44, 50 (2018)

6. I. E. Gonenc and J. P. Wolflin, Coastal Lagoons: Ecosystem Processes and Modeling for Sustainable Use and Development (CRC Press, 2004)

7. E. Wolanski, A. Newton, N. Rabalais, and C. Legrand, (2013)

8. F. de A. Esteves, A. Caliman, J. M. Santangelo, R. D. Guariento, V. F. Farjalla, and R. L. Bozelli, Brazilian J. Biol. 68, 967 (2008)

9. N. Mejjad, A. Laissaoui, O. El-Hammoumi, M. Benmansour, S. Benbrahim, H. Bounouira, A. Benkdad, F. Z. Bouthir, A. Fekri, and M. Bounakhla, J. Radioanal. Nucl. Chem. 309, 1133 (2016)

10. N. Mejjad, A. Laissaoui, A. Fekri, A. Benmhammed, O. El Hammoumi, and E. K. Cherif, ACM Int. Conf. Proceeding Ser. (2020)

11. M. Maanan, A. C. Ruiz-Fernández, M. Maanan, P. Fattal, B. Zourarah, and M. Sahabi, Int. J. Sediment Res. 29, 1 (2014)

12. B. Zourarah, M. Maanan, C. Carruesco, A. Aajjane, K. Mehdi, and M. Conceição Freitas, Estuar. Coast. Shelf Sci. 72, 359 (2007)

13. M. Elliott, D. Burdon, J. P. Atkins, A. Borja, R. Cormier, V. N. de Jonge, and R. K. Turner, Mar. Pollut. Bull. 118, 27 (2017)

14. E. R. Carr, P. M. Wingard, S. C. Yorty, M. C. Thompson, N. K. Jensen, and J. Roberson, Int. J. Sustain. Dev. World Ecol. 14, 543 (2007)

15. D. J. Rapport, Stat. Canada 11-510, Ottawa, 1979 (1979)

16. OECD., O. de coopération et de développement économiques, O. Staff, and D. (OECD) Staff, Environmental Indicators: OECD Core Set (OECD, 1994)

17. M. N. Miranda, A. M. T. Silva, and M. F. R. Pereira, Sci. Total Environ. 718, 134968 (2020)

18. B. El Mahrad, S. Abalansa, A. Newton, J. D. Icely, M. Snoussi, and I. Kacimi, Front. Environ. Sci. 8, (2020)

19. H. Karim, E. Omar, I. Mohammed, L. Jamila, A. 
Benyounes, E. Zineb, etOrbi Abdellatif., and M. Ahmed, Int. J. Adv. Res. 5, 2015 (2017)

20. K. Hilmi, V. G. Koutitonsky, A. Orbi, J. I. Lakhdar, and M. Chagdali, African J. Aquat. Sci. 30, 1 (2005)

21. E. T. Du, (n.d.)

22. K. El Khalidi, B. ZOURARAH, and A. AAJJANE,
Estud. Do Quaternário 7, 73 (2011)

23. A. Makaoui, M. Idrissi, A. Agouzouk, J. Larissi, T. Baibai, Z. El Ouehabi, M. A. Laamel, I. Bessa, O. Ettahiri, and K. Hilmi, Eur. Sci. Journal, ESJ 14, 93 (2018) 